\title{
A função transformadora da arte na cultura da indiferença
}

The transforming function of art in the culture of indifference

\section{Bruna Mello da Fonseca' e Liza Sanvito Andreazza Corso ${ }^{2}$}

Resumo: A arte nasce paralela ao processo evolutivo e a concepção do homem enquanto espécie. A psicanálise, por sua vez, nasce a partir da criatividade de seu criador e, em muito, fomentada pelo interesse que nutria pela a arte e literatura. Ao longo de sua obra, Freud ocupa-se de entender o homem através da arte - arte esta que desvela o homem - bem como compreender sua função e relação com os processos inconscientes de ordem subjetiva. Assim, alinhando psicanálise e arte, subjetivo e social, propomos a análise da função transformadora da arte na cultura vigente onde predominam vivências de indiferença, a partir das quais os sujeitos são marcados pelo trauma, pela exclusão e pela marginalidade. Entendemos a arte como uma possível saída para alteridade e que esta representa um rompimento com as demandas contemporâneas que prezam o imediatismo, o consumo, a performance e que deixam de lado o que há de mais singular em cada um. Dessa forma, a arte surge enquanto um dispositivo capaz de dar voz ao indizível, de dar forma ao irrepresentável, de alcançar os que sofrem, de reconhecer o ilógico - tal como o faz a psicanálise.

Palavras-chave: Psicanálise; Arte; Indiferença.
Abstract: Art has born parallel to the evolutionary process and the conception of man as a species. Psychoanalysis, on the other hand, has born from the creativity of its creator and, in much, fostered by the interest he had in art and literature. Throughout his work, Freud is concerned with understanding man through art - art that unveils the man - as well as understanding it's function and relationship with unconscious processes of subjective order. Thus, aligning psychoanalysis and art, subjective and social, we propose the analysis of the transforming function of art in the current culture where experiences of indifference predominate, from which the subjects are marked by trauma, exclusion and marginality. We understand art as a possible way out of otherness and that it represents a break with contemporary demands that value immediacy, consumption, performance and that leave aside what is most unique in each one. Therefore, art arises as a device capable of giving voice to the unresothing, of sothing to the unrepresentable, of reaching those who suffer, of recognizing the illogical - as psychoanalysis does.

Keywords: Psychoanalysis; Art; Indifference.

\footnotetext{
1 Psicóloga. Psicanalista pela Sigmund Freud Associação Psicanalítica. Sócia Efetiva da SPRGS e Coordenadora do Comitê de Psicanálise - gestão 2020/2021. E-mail: bruna.fonsecam@gmail.com

2 Psicóloga. Psicanalista em formação pela Sigmund Freud Associação Psicanalítica. Membro associado da Sigmund Freud Associação Psicanalítica. E-mail: lizacorso@outlook.com
} 


\section{Psicanálise e arte: telas possíveis}

Sigmund Freud questiona o quanto o processo criativo de um sujeito está ligado às suas experiências primeiras e convida-nos a pensar a fantasia enquanto uma possibilidade desde a infância. A abertura promovida pela escuta da bela indiferença, permitiu pensar o papel do simbolismo na arte. Uma vez que as fantasias agora encontram lugar, Segal (1993) propõe que a arte pode ser compreendida como a "expressão simbólica suprema da fantasia" (p. 85).

Segal (1993) entende que o ponto em comum entre artista e devaneador é que ambos criam um mundo fantasístico em que podem satisfazer seus desejos inconscientes, que seriam impossibilitados pelo recalcamento. Salienta que o ponto de diferença entre eles se dá no momento em que o artista retorna a realidade ao criar uma obra que canalize e dê sentido ao seu devaneio, o que se assemelha, segundo a autora, ao brincar infantil, a este fort-da que vai e volta, que circula entre a realidade desejante e a realidade da censura e que produz algo com este impedimento. Assim, faz-se necessário também que o desejo permaneça com disfarces e símbolos, tal como o sonho; e, por fim, é necessário que 0 artista nos dê"o prazer estético que nos distrai do pensamento oculto - um prazer que nos suborna aceitar o pensamento ocultado" (p. 88).

Para Castro (2013),"0artista deve romper com aquilo queéconhecido para impor-se, uma ruptura que deve abalar todos os significados para que o estado caótico possa gerar um novo começo, determinado pela vontade do artista" (p. 154). Para que haja desejo, é necessário antes que haja o reconhecimento do sujeito. Equando o sujeito é reconhecido tão somente por seu estado caótico, qual o papel da arte e da psicanálise? 0 que podem fazer por este para que venha a ser sujeito? Nesse sentido, tanto a psicanálise quanto a arte - propostas disruptivas - viabilizam o rompimento com o conhecido, com o repetido, eassim, considerando a subjetividade do artista/analisando, criam novas perspectivas e saídas para a limitação produzida pelos estados de exceção.

\section{Sobrevivendo na indiferença}

Desenhos, letras, riscos: é do homem fazer registros, buscar a criação de representações, cada qual em seu contexto, a fim de contar sua história, introduzir uma narrativa. A arte enuncia e denuncia, propõe deslocar as relações de poder, tirando da margem e transferindo para o centro um olhar que vê e aponta outras direções discursivas, legitimando, assim, o valor de narrativas potentes e micropolíticas. Aparece, então, como uma possibilidade de saída daqueles que estão excluídos, vivendo a indiferença do mundo para com eles.

Entendemos a indiferença como a impossibilidade do sujeito de ser olhado, ser enxergado e compreendido pelo outro. 0 traumático é ser inviabilizado em sua condição de ser. São sujeitos que marcados pela violência, pelo abandono, pela marginalidade não tiveram a possibilidade de brincar, de devanear. Foram tomados abruptamente pelo solavanco da violência, tiveram que investir toda sua energia psíquica na reorganização e na manutenção precária de sua vida. Dessa forma, entendemos que a cultura vigente perpetua tais vivências, ou melhor, tais sobrevivências, uma vez que o que impera nos tempos atuais éa lógica do consumo, da produção, do imediatismo e da competitividade. Devido a precariedade do investimento no sujeito e a consequente falha narcísica, podemos pensar o processo criativo como possível alternativa à fragilidade dos que não foram devidamente catexizados, dos que não foram suficientemente olhados. À vista disso, a arte surge como uma saída ao trauma da indiferença, uma possibilidade que se pinta.
Segundo Conte (2006)“(...) como se pode ver a ligação entre a psicanálise e a arte é tão estreita que o próprio método psicanalítico tem suas raízes ancoradas nela" (p. 430). A arte, em sua eterna correlação com a psicanálise, apresenta-se como um dispositivo que oferece aos sujeitos o contato com sua própria intimidade, com seu próprio inconsciente disposto em imagens e, assim, centraliza o lugar do sujeito frente ao social. Possibilita a capacidade de expressão, de nomear e figurar seus conflitos e 0 redimensiona frente a cultura, posto que através da arte o sujeito convoca o olhar do outro, grita e pinta para ser escutado.

Inúmeros são os exemplos de sujeitos que viviam barrados pela indiferença e que encontraram na arte um lugar de nomeação e de rompimento com a condição de não existência. Nise da Silveira revolucionou o conceito de "loucura" ao trabalhar com pacientes psicóticos internados, relegados ao esquecimento, tratados como insanos, descartados em manicômios. Através da terapia ocupacional e da possibilidade da criação artística, Nise lhes viabiliza a condição de sujeitos desejantes e, por conseguinte, de autores de sua história, agora contada pelas tintas.

Entre Bachelard e Sartre, encontrava-se Nise. Em um ambiente completamente desumanizado, onde as máquinas ganhavam espaço, disruptivamente Nise traz o pincel. Através de sua sensibilidade e capacidade de enxergar 0 outro como outro, a psiquiatra alagoana inaugura a Terapia Ocupacional no hospital psiquiátrico Engenho de Dentro, revolucionando a história da medicina ao romper com a lógica manicomial. Promove um espaço onde é possível circular a afetividade e, assim, a criatividade, dando forma à construção do sujeito. 0 hospital, que era cenário de inúmeras violências, passa a ser palco de histórias nunca antes escutadas. Nise se dispõe a escutá-las, a empatizar e a reconhece-los como sujeitos.

Neste contexto lembramos de Adelina, paciente de Nise a qual tomaremos como ilustração. Adelina chega ao hospital em 1937 apresentando irritabilidade e humor sombrio. Sua mãe relatava que Adelina teria sufocado seu gato de estimação. A paciente carregava em sua história a dor de um amor impossibilitado por sua mãe excessivamente invasiva. Barrada na sua condição de mulher, torna-se silenciosa e agressiva. No hospital, é diagnosticada com esquizofrenia, passando a ser tratada com macrodoses intravenosas e eletrochoques. Em 1946, chega à Terapia Ocupacional e rapidamente pega tintas, pincel e uma tela, entregando-se à pintura - e mais tarde à escultura. Seus primeiros desenhos representavam mulheres, gatos e plantas com suas metamorfoses vegetais. Adelina entrega sua pintura dizendo "eu queria ser flor". Nise observa suas produções: após 9 anos de internação a paciente pinta justo aquilo que marcou sua história, possibilitando dar forma ao que Ihe aprisionava. Ao longo dos anos, foram aparecendo em suas esculturas mães terroríficas de grandes mãos e rostos bravos, e, consequentemente, a agressividade de Adelina deixa de aparecer nas relações. 0 terceiro e último movimento artístico da paciente passa a ser o retrato de uma mãe amorosa que traz em si o coração fora do peito, despotencializando-a em sua maldade e permitindo-se, inclusive, enamorar-se novamente.

Torna-se possível encontrar através da arte uma posição de maior valor no discurso social, mas, sobretudo, o reconhecimento da existência destes que ficam à margem. Possibilita ao sujeito encontrar-se e redimensionar sua vida, tensionando os destinos instituídos a priori, introduzindo a escuta a partir de interrogações que visam a alteridade e que constituem sujeitos de desejo. Assim sendo, é o reconhecimento da arte, literatura, entre outras formas de expressão cultural enquanto potencialidades, enquanto formadoras de 
sujeitos de valor que podem franquear os espaços que transformam margem em centro, palavra em emoção.

Através da arte cria-se a possibilidade de dar voz aos que foram silenciados, de produzir um efeito subjetivante, pessoal, mas também produzir um efeito global, convocando a um pertencimento, a um senso de cultura e de coletividade, ser e ser social, rompendo com os muros institucionais e psíquicos.

\section{Entre pincéis e divãs, o sensível}

Blanchot, escritor ensaísta, escreve: "habitar a sua própria língua como uma língua estrangeira, assim você inventa uma coisa nova"; se distanciar do conhecido, permitindo-se a experiência do estranhamento, deixar-se tocar diante daquela narrativa que é subjetiva, logo desconhecida. Pensando desta forma, acrescentaríamos: assim, possibilita a escuta do diferente, viabilizando a proposição do novo. 0 novo que quebra, transgride, faz fissuras, promovendo um espaço de perguntas e não certezas. Em suma, a novidade proposta concede lugar ao desabrochar da novidade do outro. Assim questionamo-nos: não seria esta uma aproximação com o próprio fazer analítico? Eainda: A condição para ser um artista/analista, e não apenas dominar uma técnica, estaria relacionada a capacidade de alcançar o campo da dimensão estética deste?

Sandor Ferenczi foi o primeiro psicanalista a pensar sobre pacientes com dificuldade em fantasiar, pacientes não neuróticos, - tais como os de Nise da Silveira - com questões importantes de falha no processo de simbolização e, assim, em seguir a associação livre. Um "enfraquecimento de competência fantasística e imaginativa", conta Daniel Kupermann (2008). Pensando acerca da clínica, Ferenczi (1928) propõe o conceito de "tato" e empatia. Para ele "empatia é a faculdade de sentir dentro", flexibilidade esta que não exclui a neutralidade de forma alguma, mas pelo contrário, aponta para a segunda regra fundamental como alicerce necessário à elasticidade - afetamos e deixamos afetar. Freud defende a existência do sujeito do inconsciente, do ilógico, do atemporal, referindo não sermos donos de nossa própria casa. Assim, existimos onde não pensamos e é neste momento que estamos desnudos diante do outro, diante da arte, diante de nós. "Sentimos com", sentimos dentro, deixamos tocar e tocamos - eis a orquestra subjetiva e poética do ofício analítico. Nise se deixou afetar pelo horizonte cinza de seus pacientes institucionalizados e, somente a partir dessa reverberação em si, pode convidá-los a colorir seus mundos.

A psicanálise e a arte dialogam no encontro do sensível, o espaço de escuta viabiliza apropriar-se da sua história e construir narrativas, fazendo-se possível compreender ambas como práticas vanguardistas. Uma via facultativa à expressão do mortífero, do melancólico, do bucólico como possibilidade de ressignificação, utilizando, muitas vezes, dos arquétipos para o processo de simbolização. A arte não teme as fantasias. Divãs, palavras, pincéis e tintas: ferramentas que representam, dão dimensão e possibilitam um contorno, justamente 0 que carecem tais sujeitos, cujas constelações psíquicas foram tão pouco investidas.

Visando alavancar uma reflexão, tomando emprestada as ideias do diálogo entre Silva (2017) e Tessler (2002), compreendemos a arte como uma janela, uma abertura, a qual propicia contato com o mundo externo, com a realidade factual. Em casos nos quais o submetimento predominou, em situações nas quais o sujeito sentiu na pele a indiferença do mundo, entendemos que a arte pode colocar-se como uma janela entreaberta, como uma janela fechada, porém com persianas permitindo que uma fenda, que um facho de luz penetre e que se crie visibilidade onde antes era escuridão. A arte bem como a psicanálise e o fazer analítico, a partir da fenda, do vazio, do hiato, possibilitam a criação de processos de subjetivação, pois ao envolver-se com a obra o sujeito escreve e inscreve contorno. Propicia, portanto, construção onde só houve o irrepresentável.

Entendemos a arte como uma tentativa de encontro dialético, que possibilita a transformação e assim, trans-forma, ou seja, estaria para além da forma. Seguindo esta lógica, compreendemos a arte como a vontade de ser, uma aposta na condição de existir, na cultura. Frayze Pereira (2005) refere que a obra é resultante do encontro entre a produção e o estranhamento do sujeito que olha, cria-se e cria a si. Assim, torna possível "uma silenciosa abertura ao que não é nós e que em nós se faz dizer" (Pereira, 2005). Prescindimos, portanto, do sensível frente ao encontro com o outro para que possamos escutar a sua arte.

\section{Referências}

Conte, J. (2006) Arte e Psicanálise. Psicanálise - Revista da Sociedade Brasileira de Psicanálise de Porto Alegre/Sociedade Brasileira de Psicanálise de Porto Alegre, 8 (2).

Castro, D. F. (2013). Literatura, teatro e psicanálise: quando a ansiedade é influência. In: Mello, A. M. L., da Silva, C. G., de Farias, A. B., dos Santos, M. L., \& de Souza, R. T. (Eds.). Literatura e psicanálise: Encontros contemporâneos. Editora Dublinense.

Ferenczi, S. (1928). Elasticidade da técnica psicanalítica. Obras Completas, Ed. Martins Fontes.

Frayze-Pereira, J. A. (2010). Arte, Dor-Inquietudes entre Estética e Psicanálise. Ateliê Editorial.

Freud, S. (1908/1996). Escritores criativos e devaneios. In S. Freud (Ed.), Obras psicológicas completas de Sigmund Freud, IX. Rio de Janeiro: Imago.

Kupermann, D. (2008). Presença sensível: cuidado e criação na clínica psicanalítica. Civilização Brasileira.

Segal, H. (1993). Sonho, Fantasia e Arte. Rio de Janeiro: Imago.

Silva, S. M. (2017). Leituras psicanalíticas da arte: problemáticas. In: Kruger, L.; Refosco, L. L.; Silva, S. M. (orgs). Interlocuções na fronteira entre psicanálise e arte. Porto Alegre: Artes \& Ecos.

Tessler, E. (2002). Tudo é figura ou faz figura. Psicanálise, arte e estética da subjetivação. Rio de Janeiro: Imago. 